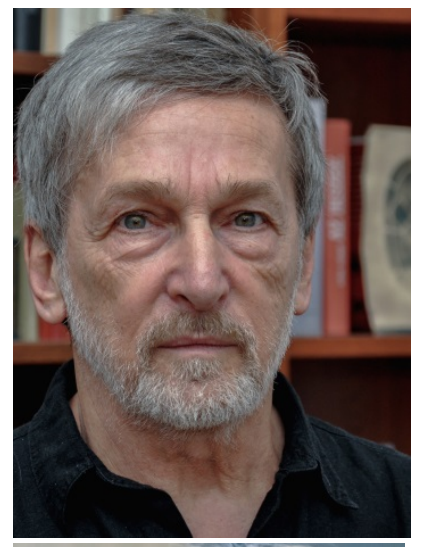

Gábor Csanádi, Candidate of Sociology ELTE University, Centre for Urban and Regional Research, Emeritus Director

Budapest, Hungary gcsanadi@tatk.elte.hu

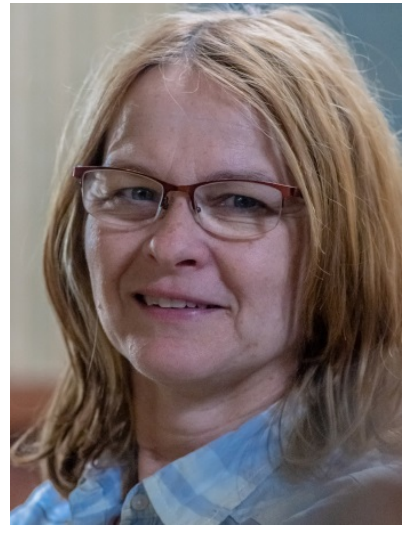

Adrienne Csizmady, $\mathrm{PhD}$, director of the Institute of Sociology of the Hungarian Academy of Sciences

Budapest, Hungary csizmady.adrienne@tk.mta.hu

DOI 10.31554/978-5-7925-0571-1-2019-2-152-156

\title{
RESIDENTIAL SEGREGATION AND SUBURBAN DEVELOPMENT IN POST-SOCIALIST AGGLOMERATIONS
}

The post socialist transformation of the Hungarian society is clearly visible in the process of the changes in suburbanization. We will explore the social heterogeneity of the participants, describing which groups were able to gain and which groups loose. We try to understand the reasons on the micro and macro level, and to give some light to the consequences in the segregation within the settlements of the agglomeration area.

Keywords: residential segregation, suburban development, post-socialist agglomeration, Budapest. 
The example of the Budapest agglomeration shows the reasons behind the acceleration of suburbanisation after 1990 and how the agglomeration settlements were affected by this process.

Privatization of rental housing has to be considered as a significant motivation factor in the high level of mobility following the change of regime. Housing privatization has had a variety of impacts on different stakeholder groups. Among other things, it has significantly increased the chances and constraints of relocation.

Migrants from Budapest cannot be considered as a homogeneous population. There are three major types. Not only are these three spatially mobile groups belong to different social statuses, but the factors driving mobility and the consequences of moving are also fundamentally different.

The high status group

The first group is the high-status population, whose suburbanisation movement is now considered "trivial", as it is well known from everyday experience and from American and Western European literature. One of the important consequences of the transition to market economy conditions was that this type of suburbanisation relocation, which is typical of developed western societies, was also widespread in Hungary. At the same time, this group is able to occupy what it considered to be the most favorable spatial position, not only by taking advantage of its favorable market position, but also by transforming it in the housing market by using its well-established status in social structure. However, moving practices do not simply follow behavior that optimizes the market situation. A closer analysis of the data reveals for example, that the "need for quality of the natural environment" as an explicit driving force to suburban movement often declared by members of that social group - only legitimizes the need for middle and higher status groups to move to an environment of the desired or real social status. It can be shown that, for groups where the directions and modalities of spatial mobility are relatively free to choose, the need for an "appropriate status" environment plays a more important role in determining the direction of the move than practical considerations. Of course, the fact that the main motive for moving to a residence of a suitable status does not mean that a residence approached in this way is not favorable in practical terms. Furthermore, it is also clear that when these high-status suburban housing estates are created with temporarily low levels of infrastructure provision, the residents will exploit their - not insignificant - pressure to eliminate these rela- 
tive disadvantages and, in the short term, the area become advantageous in these aspects as well. This means, putting pressure on local decision-makers, in particular the municipal development, town planning, and regulatory staff and politicians, to pursue their 'legitimate' local interests.

But precisely because of their high status, they are not only able to influence the decisions of a small town, but there are several signs that they are trying to make more comfortable their transport from their place of residence to the capital, for example. Similarly, decisions at regional level beyond the competence of the municipality should be made in order to mobilize all societal resources to ensure that the symbolic residences chosen according to the status of the high-status population actually have the highest possible public goods.

\section{Medium status group}

The second type of movers consist of middle class and lower middleclass groups. In their case, the relocation took place somewhat later than in the case of the previous group and moved to less favored settlements, or to lower status parts of the medium status towns and villages. In their case, compared to the previous group, the ecological position of the Budapest residence was relatively less favorable. The most important motive of moving in their case was the "danger" in the ecological position within the capital. They realized that the neighborhood may become slumish for various reasons. In this group, the general social status was higher than the ecological status, and the suburban move was caused by the tension of this inconsistency. As a result, during the suburbanisation process, these social groups may, of course, target settlements with a lower status than their first group, since their financial and social capital is less strong. At the same time, however, the direct improvement in the housing situation seems to be important. For the high-status group, the Budapest apartment was already top-status socially and physically as well . That is why for that group , the objective characters of the housing situation in Budapest may not have been a major stressor here, while the symbolic value of the new housing status may have dominated. In the middle-status group, however, relatively less favourable housing conditions in Budapest acted as repulsive factors, so rational decision is more obvious in the sense that there are significant changes in several parameters of the home.

The move was made possible not least by the privatization process of the 1990s in cases where the purchase of a former rental home can be consi- 
dered as a relatively significant capital injection for this group as well. Of course, since these city-apartments were located in a much lower status area than in the case of previously mentioned group, this capital was enough to become a market buyer (as a builder)

a, in the middle-status settlements of the agglomeration, and

b, only with relatively significant family-capital additions, like earlier weekend house sales, financial help of parents, etc. Thus, moving means more or less exhausting the possibilities of the wider family, so in a sense the step is even more significant than in the case of the first group, so the search for a better home plays a bigger role here.

What are the consequences of moving out this two social groups in the area they? The high-status areas of Budapest abandoned by the first group still represent the highest ecological areas of the city. However, the former areas left by the second group may significantly increase the risk of becoming slum area, precisely because of the moderate or lower status of the Budapest residence. Thus, contrary to public opinion, the risk of deterioration in certain inner areas of the city is not related to the outflow of highest-status people from the city, but rather to the suburban movement of middle-status from the slum-dangerous neighborhoods,. However, due to the boom in the real estate market in recent years, it is precisely these areas of the city that are undergoing development.

\section{Low status group}

Finally, there is a relatively significant type of move that is often referred to as poverty suburbanization. People in this category are forced to leave their place of residence because they are too poor to bear the increased (increasing) housing and maintenance costs. In their case, poor housing is often accompanied by the existence of arrears in rents or electricity. These areas include, for example, poor housing estates in the capital, slum areas in inner districts, courtyards in condos, and inferior suburban homes. For this group, the pessimistic scenario of the privatization of the 1990s prevailed. From the privatization of housing, it is mainly the rising costs that they feel. Ownership has had only a minimal positive effect, as their new housing properties - and thus their market value - are low and the additional capital they mobilize is so modest that their room for maneuver is severely reduced. This is compounded by the general problem that, according to experience, several generations of "learning" are needed for a disadvantaged social group to be able to manage, operate, the opportunities provided in principle by the social 
environment for its own benefit. This is due, among other factors, to the group's low level of education, which has obviously led them to learn less about market conditions than their more well-off counterparts.

In their case, moving out is a pre-disaster escape attempt. They try to utilize a characteristic type of family capital. That is connected to the historical fact, that a significant part of this group of families ( or at least their parents or even grand-parents) moved to Budapest from the eastern, north-eastern part of the country in the decades following the Second World War during the process of colhoz organizing and the socialist industrialization . The money available for relatively low-value housing in Budapest, and the mobilization of relative's sources - also living in relatively poor neighborhoods in the country - is not enough to find any solution even in the more remote areas of the conurbation. Thus, these families return to a deserted, relatively poor settlement in the country, left thirty or forty years ago, and use their capital to make these half empty and possibly poor condition houses moderately usable. In these places, non-cash forms of family support may also be associated with modest capital, so the prospect of an acceptable solution for them at first glance is outlined. The success of a relocation depends on whether or not that given region of the country can recover from depression or not. As most of the target settlements in question are located in the poorest areas of the country, although the housing situation seems to have been resolved, livelihood problems are not diminishing but may even increase.

Perhaps the most important conclusion from our analysis is that the evolution of the city and its environment simultaneously reflects the consequences of "spontaneous” processes and power-planning interventions.

Thus, besides the spontaneous aspirations of the stakeholders, the complex system of expert and political decisions basically determines the conditions in which spontaneous aspirations can prevail. 